\title{
Non Suicidal Self Injury in Adolescence: Psychosocial Predictors
}

Victor Ferreira Leita ${ }^{1^{*}}$, Joana Ferreira ${ }^{1}$, Luisa Veiga ${ }^{1}$ and Jose Garrido ${ }^{2}$

${ }^{1}$ Child and Adolescent Psychiatrist, Centro Hospitalar e Universitário de Coimbra, Coimbra, Portugal

${ }^{2}$ Child and Adolescent Psychiatrist and Head of Department, Centro Hospitalar e Universitário de Coimbra, Coimbra, Portugal

*Corresponding author: Vítor Ferreira Leite, Child and Adolescent Psychiatrist, Centro Hospitalar e Universitário de Coimbra, Coimbra, Portugal, Tel: +351 239400 400; E-mail: vbruno.pedopsiq@gmail.com

Received date: October 05, 2017, Accepted date: October 11, 2017, Published date: October 16, 2017

Copyright: (C 2017 Leite VF, et al. This is an open-access article distributed under the terms of the Creative Commons Attribution License, which permits unrestricted use, distribution, and reproduction in any medium, provided the original author and source are credited.

Abstract
Non-suicidal self-injury (NSSI) has its typical onset during adolescence and usually configures a maladaptive
coping strategy that serves numerous functions. Adverse psychosocial situations are related with an increased risk
for NSSI. The objective of this work was to identify the most prevalent psychosocial risk factors for NSSI during
adolescence and statistically significant associations between them. A convenience sample of 50 adolescents with
identified history of NSSI was used. Each case was searched for the Abnormal Psychosocial Situations (APS)
contemplated in the psychosocial axis (Axis V) of the International Classification of Diseases (10 edition). The 10
more prevalent APS were present in at least $50 \%$ of the subjects. Several statistically significant associations
between APS were identified, signalizing certain patterns of associations that suggest increased risk for NSSI. A
proper assessment of the psychosocial contexts may allow identification of youth at risk for NSSI, and thus the
institution of early intervention programs.

Keywords: Adolescent psychiatry; Non-suicidal self-injury; Psychosocial factors; ICD 10; Risk factors

\section{Introduction}

\section{The crisis and the symptom}

Adolescence is a developmental stage challenged by profound changes that tend to culminate in normative outcomes. Moments of discontinuity, emotional instability, identity crisis and intergenerational conflict may all be part of a normative adolescence (the "normative adolescent turmoil" by G. Stanley Hall and the "adolescent crisis" by Erik Erikson refer, moreover, to this same finding) $[1,2]$. However, the plethora of changes that occur during this transitional period can also work as a fertile ground for the development of emotional, psychological and relational disorders that ultimately may condition the emergence of psychopathology [3].

The authors find it difficult to dissociate the growing observance of NSSI from the paradoxical evolution of our western contemporary society [4]. In a tumultuous context of social and financial crisis, people's sense of security and stability is systematically undermined. The task of forecasting a sustainable life project that values family and parenting in its fullness is therefore menaced. Restraints to the autonomisation process are increasingly delaying marriage and childbirth, fostering a suspension of adult roles and responsibilities"psychosocial moratorium" $[2,5,6]$. We are therefore standing before a trend toward the prolongation of "adolescence". The more complex a society is, the longer and turmoiled will also be the process of adolescence $[5,6]$.

To fully understand health and illness, the Biopsychosocial Model (which imposes evaluating and framing the patient within a multiaxial system) must systematically be considered from a developmental perspective $[7,8]$. It is of the outmost importance to identify the various factors involved in the pathological process: protection and resilience factors, risk and vulnerability factors, precipitating and maintenance factors (Stress-vulnerability Model) (Figure 1).

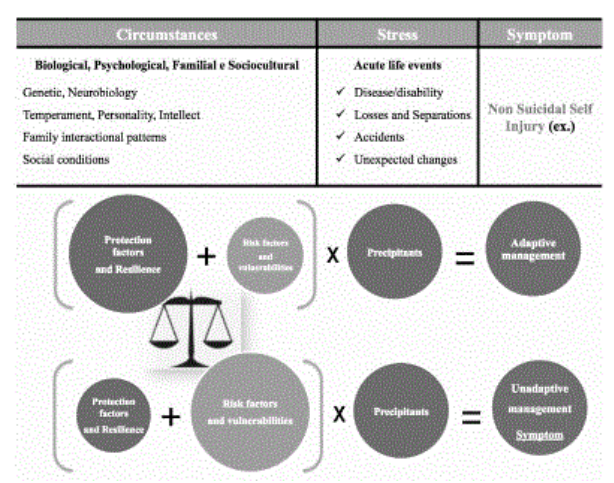

Figure 1: The symptom explained by the Biopsychosocial Model (Engel G.) and by the Stress-vulnerability Model (Zubin J. and Spring B.) (Author's adaptation).

A key aspect of this dynamic process lies in the relationship that the subject establishes with his own body, which is a privileged means of symbolic expression of the young's conflicts and relational styles [9]. The body is simultaneously a representation of the Self, justifying the large share of time invested in efforts to attune with the ideal appearance [10]. In addition to its role as a carrier of pleasure and anxiety, the body may also constitute a vehicle for painful and selfinjurious behaviour, as a means to cope with conflicts experienced as overwhelming. The symptom comes often as a behavioural manifestation of a psychological conflict that is normative and transient, frequently reactive to certain situations (e.g., difficulties in academic activities, interpersonal relationships, dealing with frustrations, regulation of emotions, mentalization, cognitive 
development). However, they should draw our attention to a turmoil and solitary process with unfavourable outcomes.

\section{NSSI in the literature}

NSSI has its typical onset during adolescence. There is a rapid increase during the first years of adolescence (puberty), with a higher prevalence in the female gender (especially between thirteen and fifteen years old) $[11,12]$. According to community samples, between $10 \%$ and $18 \%$ of the adolescents display NSSI at least once in their lifetime [13-16]. From clinical samples, prevalence will range from 40 to $82 \%[14,17]$.

NSSI may configure a maladaptive strategy to cope with conflicts experienced as overwhelming; a means of self-punishment or selfdirected anger; may enclose a communicative function (to get affection, to connect with peers who display similar behaviour, to metacomunicate); a way to interrupt dissociative states or to achieve deep states of excitement; an effort to control sexual pulsions or to resist thoughts of suicide $[10,17]$.

Despite the fact that NSSI is prevalent and impairing in adolescents, it has not been given any psychopathological significance except as a symptom of BPD until the fifth edition of the Diagnostic and Statistical Manual of Mental Disorders (DSM-5, American Psychiatric Association) [18]. DSM-5 places NSSI in its Section III: Emerging Measures and Models, as a condition that requires further study. According to DSM-5 criteria, NSSI implies repeated intentional selfinflicted damage to the surface of the body (cutting, burning, stabbing, hitting, excessive rubbing) with the expectation that the injury will lead to only minor or moderate physical harm (i.e., there is no suicidal intent). Substance intake in an excessive dose, illegal drug or recreational substance use (as an intentional way of self-injury) and the ingestion of a non-ingestible substance may also configure NSSI behavior.

The Multiaxial Classification of Child and Adolescent Psychiatry (ICD-10, WHO) [19], classifies them in the Axis IV (Medical Conditions), with the code X from chapter XX (Intentional self-harm), including any way, regardless of the method of inflicting bodily harm. Code X, however, does not establish any difference between attempted suicide and parasuicide, both included in the general category of selfinjury (thus imposing the need to evaluate the method, lethality, intentionality...).

\section{Psychosocial factors and NSSI}

Although a great body of research has been dedicated to the subject of NSSI in the last recent years, little is known about the relation between specific aspects of the psychosocial profile of the youth and the incidence of NSSI.

According to literature, it was observed increased risk for NSSI in face of: family history of suicidal behaviour [20,21]; difficulties in the parent-child relationships, with perception by the patient of poor communication and lack of warmth [22-24]; physical or sexual abuse [25-28]; social exposure to NSSI ("social contagion") [29,30]; acute life events (rejection, dispute, loss, etc.) [25,31-33]; bullying e cyber bullying [13,34]; migration, social transplantation, adverse sociocultural discrimination [35,36]. It is advised that all young people who express suicidal ideation should receive a complete psychosocial assessment in order to identify all the risk and protective factors, mental illness, as well as a full understanding of the self-injurious process in the individual [37-40]. An adequate psychosocial assessment was associated with decrease in the repetition of NSSI behaviour [41,42]. Psychosocial assessment should be the basis of clinical management and goal setting.

\section{Objectives}

With this paper the authors set out to identify the most prevalent psychosocial risk factors for NSSI during adolescence and to identify statistically significant associations between them. The main focus lays on the identification of populations at risk, aiming to a timely intervention. Little is known about the relation between specific abnormal psychosocial situations (APS) and NSSI in adolescence. As to the authors' knowledge, this is the first research with such goals.

\section{Methods}

This is an observational cross-sectional retrospective, exploratory study. The authors used a convenience sample of 50 outpatient adolescents aged 12-17 years old, from Coimbra's Child and Adolescent Psychiatry Department. Subjects included belonged to the author's list of patients and the inclusion criteria consisted in identified current or past history of NSSI (at least one episode of self-injurious behaviour in the last six months previous to assessment), with data being collected along a period of six months. The present sample is part of a larger on-going study about this same matter.

As an auxiliary to the interview, the authors resorted to the "Multiaxial classification of Child and Adolescent psychiatric disorders: ICD-10", specifically to its fifth axis - Associated Abnormal Psychosocial Situations. This axis comprises nine dimensions:

- Abnormal intrafamilial relationships

- Mental disorder, deviance or handicap in the child's primary support group

- Inadequate or distorted intrafamilial communication

- Abnormal qualities of upbringing

- Abnormal immediate environment

- Acute life events

- Societal stressors

- Chronic interpersonal stress associated with school/work

- Stressful events/situations resulting from the child's own disorder/ disability (Figure 2).

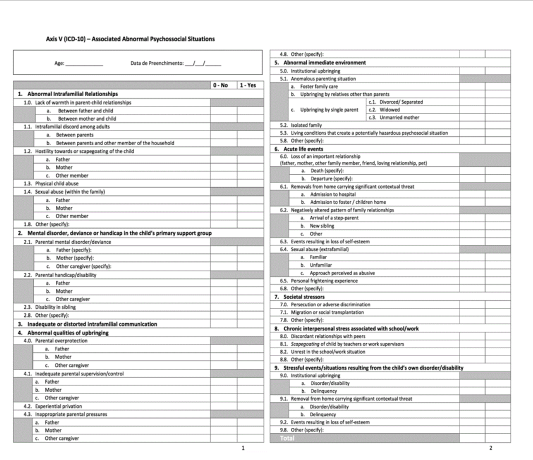

Figure 2: Script checklist based on the Axis V (ICD-10)-abnormal psychosocial situations. 
Page 3 of 6

Each of the 50 patients was searched for the several APS contemplated in this axis. Specifically for this purpose and to aid in the clinical interview, the authors compiled a checklist script. The script checklist comprised 67 APS to be asked.

Data were first submitted to a simple observational analysis, followed by a statistical analysis resorting to the software IBM SPSS Statistics ${ }^{\bullet}$, v.20 (Windows).

To measure the strength and direction of the association between variables, non-parametric tests were used, namely Spearman rank correlation coefficient test. $\mathrm{P}$ values under 0.05 were accepted as statistically significant (confidence intervals 95\%). It was also considered the result of the bilateral correlation test (2-tailed).

\section{Results}

The sample comprised 50 patients with a mean age of 15.4 years. The female gender showed to prevail, representing $90 \%$ of the cases. The 10 most prevalent APS are displayed on (Table 1).

\begin{tabular}{|l|l|l|}
\hline APS & $\mathbf{n}$ & $\%$ \\
\hline Intrafamilial discord among adults (both parents) & 37 & 74 \\
\hline Inadequate or distorted intrafamilial communication & 37 & 74 \\
\hline Events resulting in loss of self esteem & 36 & 72 \\
\hline Loss of a love relationship (removal) & 34 & 68 \\
\hline Lack of warmth in parent-child relationships (father) & 32 & 31 \\
\hline Caregiver's mental disorder (mother) & 29 & 64 \\
\hline Inadequate parental supervision/control (father) & 26 & 58 \\
\hline Abnormal immediate environment (divorce/separation) & 26 & 52 \\
\hline Loss of an important relationship (death) & 25 & 52 \\
\hline Discordant relationships with peers & & 50 \\
\hline
\end{tabular}

Table 1: Distribution of the 10 most prevalent APS.

A plain observational analysis revealed that $50 \%$ of the subjects displayed the three more prevalent APS and every patient displayed at least two APS. Only 4 patients did not display any of the 5 more prevalent APS, but 14 patients (28\%) displayed all the 5 APS in association. The 3 most prevalent APS-intrafamilial discord among adults (both parents), inadequate or distorted intrafamilial communication, events resulting in loss of self-esteem-were found in $50 \%$ of the subjects. Every patient displayed at least two associated APS, with 2 individuals showing 2 APS and 1 individual with 27 APS. A mean of 12.6 APS per individual was obtained. This observation raises the question if the number of APS per subject has association with the severity of the self-injurious behaviour (matter under analysis in the authors' ongoing research). Only 4 patients did not display any of the five more prevalent APS, but 14 patients (28\%) displayed the 5 APS in association.

A great number of statistically significant associations between APS were found. For practical reasons, statistical significance between APS was only tested for the five most prevalent factors: Intrafamilial discord among adults (both parents), Inadequate or distorted intrafamilial communication, Events resulting in loss of self-esteem, Loss of a love relationship (removal), Lack of warmth in parent-child relationships (father) (Figure 3).

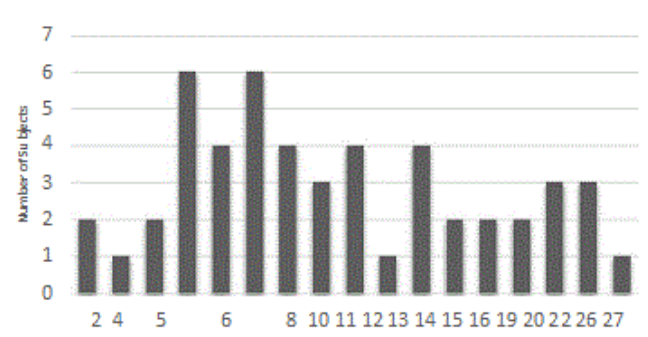

Figure 3: Number of APS per subject.

Overall, the number of associations between the five more prevalent APS and Axis V APS was high, with a total of 26 statistically significant associations.

The statistics are displayed in (Table 2).

\begin{tabular}{|l|l|l|l|}
\hline APS & r & S & Sig. (2-tailed) \\
\hline 1.1. Intrafamilial discord among adults (both parents) & 0.41 & $<0.01$ (IC 99\%) & 0.003 \\
\hline 1.0. Lack of warmth in parent-child relationship (father) & 0.475 & $<0.01$ (IC 99\%) & 0 \\
\hline 2.1. Parental mental disorder/deviance (mother) & & \\
\hline
\end{tabular}


Citation: Leite VF, Ferreira J, Veiga L, Garrido J (2017) Non Suicidal Self Injury in Adolescence: Psychosocial Predictors. J Gen Pract (Los

\begin{tabular}{|c|c|c|c|}
\hline 4.1. Inadequate parental supervision/control (mother) & 0.327 & $<0.05$ (IC 95\%) & 0.02 \\
\hline \multicolumn{4}{|l|}{ 3. Inadequate or distorted intrafamilial communication } \\
\hline 1.0. Lack of warmth in parent-child relationship (father) & 0.315 & $<0.05($ IC $95 \%)$ & 0.026 \\
\hline 1.0. Lack of warmth in parent-child relationship (mother) & 0.333 & $<0.05$ (IC 95\%) & 0.018 \\
\hline 2.1. Parental mental disorder/deviance (mother) & 0.569 & $<0.01($ IC $99 \%)$ & 0 \\
\hline 6.0. Loss of an important relationship (departure) & 0.473 & $<0.01($ IC 99\%) & 0.001 \\
\hline 6.3. Events resulting in loss of self-esteem & 0.443 & $<0.01($ IC $99 \%)$ & 0.001 \\
\hline \multicolumn{4}{|l|}{ 6.3. Events resulting in loss of self-esteem } \\
\hline 2.1. Parental mental disorder/deviance (mother) & 0.338 & $<0.05$ (IC 95\%) & 0.016 \\
\hline 3. Inadequate or distorted intrafamilial communication & 0.443 & $<0.01($ IC $99 \%)$ & 0.001 \\
\hline 4.3. Inappropriate parental pressures (mother) & 0.292 & $<0.05($ IC $95 \%)$ & 0.04 \\
\hline 5.3. Hazardous psychosocial situation (living conditions) & 0.373 & $<0.01($ IC $99 \%)$ & 0.008 \\
\hline 6.0. Loss of an important relationship (death) & 0.292 & $<0.05($ IC $95 \%)$ & 0.039 \\
\hline 6.0. Loss of an important relationship (departure) & 0.527 & $<0.01($ IC $99 \%)$ & 0 \\
\hline 9.2. Events resulting in loss of self-esteem & 0.488 & $<0.01($ IC $99 \%)$ & 0 \\
\hline \multicolumn{4}{|l|}{ 6.0. Loss of an important relationship (removal) } \\
\hline 2.1. Parental mental disorder/deviance (mother) & 0.346 & $<0.05($ IC $95 \%)$ & 0.014 \\
\hline 3. Inadequate or distorted intrafamilial communication & 0.473 & $<0.01($ IC 99\%) & 0.001 \\
\hline 4.0. Parental overprotection (father) & 0.299 & $<0.05$ (IC 95\%) & 0.035 \\
\hline 4.3. Inappropriate parental pressures (mother) & 0.321 & $<0.05$ (IC 95\%) & 0.023 \\
\hline 5.2. Isolated family & 0.299 & $<0.05$ (IC 95\%) & 0.035 \\
\hline 6.0. Loss of an important relationship (death) & 0.457 & $<0.01($ IC $99 \%)$ & 0.001 \\
\hline 6.3. Events resulting in loss of self-esteem & 0.527 & $<0.01($ IC $99 \%)$ & 0 \\
\hline \multicolumn{4}{|l|}{ 1.0. Lack of warmth in parent-child relationship (father) } \\
\hline 1.1. Intrafamilial discord among adults (between parents) & 0.41 & $<0.01($ IC $99 \%)$ & 0.003 \\
\hline 1.2. Hostility towards or scapegoating of the child (father) & 0.468 & $<0.01($ IC $99 \%)$ & 0.001 \\
\hline 3. Inadequate or distorted intrafamilial communication & 0.315 & $<0.05($ IC $95 \%)$ & 0.026 \\
\hline 5.3. Living conditions that create a potentially hazardous psychosocial situation & 0.413 & $<0.01($ IC $99 \%)$ & 0.003 \\
\hline
\end{tabular}

Table 2: Associations with the five more prevalent APS.

\section{Discussion}

Individual characteristics interplay with environmental circumstances, determining different developmental outcomes. However, despite the unpredictability inherent to this process, some psychosocial patterns seem to stand out in young patients who engage in NSSI.

We started from the hypothesis that risk factors associated to family background would play the main part, pointing out to young's perception of parental discord and lack of warmth from their parents as preponderant risk factors. The results enabled the authors to consolidate some previously published notions and to add a few others that, in their perspective, seem particularly relevant.

Not surprisingly, female gender prevailed in the study's sample. This finding is consistent with published literature. Earlier and numerous studies have shown that girls tended to internalize, while boys tended to externalize. Applied to NSSI this would lead to girls harming them, while boys would be expected to display more hazardous behaviour as a form of self-harm. However, recent studies have suggested a slight dimming of this discrepancy. The mean age of 15.4 years also comes in line with previously published literature. 
Regarding the ten most prevalent APS displayed on Table 1, intrafamilial discord among adults (both parents) and inadequate or distorted intrafamilial communication come in first and second place, respectively, substantiating one of the authors' main clinical impressions. In fact, the role of the family takes great preponderance within this list. Parental mental disorder/deviance (mother) is another unsurprising feature, since it comes in line with a great body of literature associating psychopathology in the mother with disorder in the child. Among other reasons, this should be due to the emotional and/or behavioural impact that mother's disorder may have in her parenting skills. Inadequate parental supervision/control (father) also came as extremely relevant, highlighting the importance of the father's role as a reinforcer of limits and discipline. Understandably, events resulting in loss of self-esteem also revealed to be a main APS, being one of the most consensual features of young patient are engaging in NSSI. Abnormal immediate environment (divorce/separation) as a main APS may probably be explainable by the situation of conflict to which the child/adolescent is exposed (which is inherent most of the time) instead of the separation by itself. Noteworthy, despite the preponderant role of the family within this list, discordant relationships with peers comes in tenth place, signalling the role of socialization in the adolescence.

Regarding one of the main purposes of this study, the identification of statistically significant patterns or associations, the analysis found them to exist in a considerable number. By far, the abnormal intrafamilial relationships comprised most statistically significant associations, followed by the abnormal immediate environment and the abnormal qualities of upbringing. Once again, the preponderance of the family role in the psychosocial development process comes reinforced.

Situations of intrafamilial discord among adults have shown very strong associations with lack of warmth in parent-child relationships (father), parental mental disorder/deviance (mother) and inadequate parental supervision/control (mother). These associations grant us the different contributions that paternal and maternal skills may give to the child's/adolescent's psychosocial development. The interesting observation that the lack of warmth in parent-child relationships was found to regard mainly the father, in a sample predominantly feminine, raises the question about the father's role over girls' psychosocial development. If so, this would also go in line with the authors' clinical impression. The lack of warmth in parent-child relationships (father) associated with intrafamilial discord among adults (both parents) and inadequate or distorted intrafamilial communication also deserves to be mentioned. It allows highlighting the father's role as an emotional support figure who, in the presence of intrafamilial discord and inadequate intrafamilial communication, may find his ability to convey positive affection compromised, which would be perceived by the youth as lack of affection. Or, from another point of view, the father's inability to convey positive affection may be the reason for the intrafamilial discord.

Events resulting in loss of self-esteem showed associations with the perception of loss of an important relationship (probably by the greater vulnerability to loss), inadequate or distorted intrafamilial communication, parental mental disorder/deviance (mother) and inappropriate parental pressures (that could explain feelings of low self-efficacy, if expectations are not corresponded).

Loss of an important relationship found associations with inadequate or distorted intrafamilial communication, parental overprotection, inappropriate parental pressures and isolated family.
The loss of an important relationship (departure) showed association with factors related to perception of low familiar and social support (parental mental disorder/deviance, inadequate or distorted intrafamilial communication and isolated family) or excessive intrusiveness (parental overprotection and inappropriate parental pressures).

\section{Conclusions}

This study highlights statistically significant associations between APS, which may be useful to signal high-risk patients and to promote early prevention and intervention programs. Results are in line with the existing literature, adding a more specific understanding to the relatively sparse literature describing the relationship between NSSI and APS. They are also in line with the authors' clinical impression, which set the tone for this study. Nevertheless, the present study presents some limitations. The sample size and the absence of a control group do not allow us to infer about the specificity of the APS associations with NSSI behaviour (a limitation that is being addressed in a larger ongoing study by the authors); the evaluation of the APS is submitted exclusively to the clinician's evaluation (converting this study in a non-blinded experiment) and the interobserver agreement hasn't been tested; comorbid psychopathology is not taken in consideration. This research reinforces the need for a rigorous psychosocial evaluation and for a guided intervention.

\section{Declaration of Interests}

All authors certify that they have NO affiliations with or involvement in any organization or entity with any financial interest (such as honoraria; educational grants; participation in speakers' bureaus; membership, employment, consultancies, stock ownership, or other equity interest; and expert testimony or patent-licensing arrangements), or non-financial interest (such as personal or professional relationships, affiliations, knowledge or beliefs) in the subject matter or materials discussed in this manuscript.

\section{Funding Sources}

This research did not receive any specific grant from funding agencies in the public, commercial, or not-for-profit sectors.

\section{References}

1. Ackard DM, Neumark-Sztainer D, Story M, Perry C (2006) Parent-child connectedness and behavioral and emotional health among adolescents. Am J Prev Med 30: 59-66.

2. American Psychiatric Association (2013) Diagnostic and statistical manual of mental disorders. ( $5^{\text {th }}$ edn.) American Psychiatric Publishing, USA.

3. Andover MS, Pepper CM, Ryabchenko KA, Orrico E, Gibb BE (2005) Self-mutilation and symptoms of depression, anxiety, and borderline personality disorder. Suicide Life Threat Behav 35: 581-591.

4. Beautrais AL (2001) Suicides and serious suicide attempts: Two populations or one?. Psychol Med 31: 837-845.

5. Bergen H, Hawton K, Waters K, Cooper J, Kapur N (2010) Epidemiology and trends in non-fatal self-harm in three centers in England: 2000-2007. Br J Psychiatry 197: 493-498.

6. Brent DA, Bridge J, Johnson BA, Connolly J (1996) Suicidal behavior runs in families. A controlled family study of adolescent suicide victims. Arch Gen Psychiatry 53: 1145-1152.

7. Brunner R, Kaess M, Parzer P, Fischer G, Carli V, et al. (2014) Lifetime prevalence and psychosocial correlates of adolescent direct self-injurious 
behavior: A comparative study of findings in 11 European countries. J Child Psychol Psychiatry 55: 337-348.

8. Brunstein-Klomek A, Sourander A, Gould M (2010) The association of suicide and bullying in childhood to young adulthood: A review of crosssectional and longitudinal research findings. Can J Psychiatry 55: 282-288.

9. Carvalho R, Garrido J (2005) Adolescence: Understanding models. Clin Psychiatry 26: 107-123.

10. Donald M, Dower J, Correa-Velez I, Jones M (2006) Risk and protective factors for medically serious suicide attempts: A comparison of hospitalbased with population-based samples of young adults. Austand N Z J Psychiatry 40: 87-96.

11. Dumas J (2011) Psychopathology of Childhood and Adolescence. ( $3^{\text {rd }}$ edn.), Artmed, Porto Alegre, Brazil.

12. Erikson EH (1968) Identity: Youth and crisis. W. W. Norton Company, New York, USA.

13. Evans E, Hawton K, Rodham K, Psychol C, Deeks J (2005) The prevalence of suicidal phenomena in adolescents: A systematic review of populationbased studies. Suicide Life Threat Behav 35: 239-250.

14. Fergusson DM, Horwood LJ, Lynskey MT (1994) The childhoods of multiple problem adolescents: A 15-year longitudinal study. J Child Psychol Psychiatry 35: 1123-1140.

15. Fergusson DM, Horwood LJ, Woodward LJ (2001) Unemployment and psychosocial adjustment in young adults: Causation or selection?. Soc Sci Med 53: 305-320.

16. Freedenthal S, Stiffman A (2007) They might think I was crazy: Young American Indians' reasons for not seeking help when suicidal. J Adolesc Res 22: 58-77.

17. Garnefski N, Kraaij V, van Etten M (2005) Specificity of relations between adolescents' cognitive emotion regulation strategies and internalizing and externalizing psychopathology. J Adolesc 28: 619-631.

18. Ginzberg E (1961) Values and ideals of American youth. Columbia University Press, New York, USA.

19. Goodman R, Scott S (2012) Child and adolescent psychiatry. ( $3^{\text {rd }}$ edn.), Wiley-Blackwell, Oxford, UK.

20. Hall SG (1907) Adolescence: Its psychology and its relations to physiology, anthropology, sociology, sex, crime, religion and education. Appleton, New York, USA.

21. Hawton K, Hariss L, Rodham K (2010) How adolescents who cut themselves differ from those who take overdoses. Eur Child Adolesc Psychiatry 19: 513-523.

22. Hawton K, Saunders KE, O'Connor RC (2012) Self-harm and suicide in adolescents. Lancet 379: 2373-2382.

23. Heikkilä HK, Väänänen J, Helminen $M$, Fröjd S, Marttunen $M$, et al. (2013) Involvement in bullying and suicidal ideation in middle adolescence: A 2-year follow-up study. Eur Child Adolesc Psychiatry 22: 95-102.

24. Isohookana R, Riala K, Hakko H, Räsänen P (2013) Adverse childhood experiences and suicidal behavior of adolescent psychiatric inpatients. Eur Child Adolesc Psychiatry 22: 13-22.
25. Kapur N (2013) Does clinical management improve outcomes following self-harm? Results from the multicenter study of self-harm in England. PLoS One 8: e70434.

26. Langhinrichsen-Rohling J, Friend J, Powell A (2009) Adolescent suicide, gender, and culture: A rate and risk factor analysis. Aggress Violent Behav 14: $402-414$.

27. Laye-Gindhu A, Kimberly A, Schonert-Reichl KA (2005) Non-suicidal self-harm among community adolescents: Understanding the "what's" and "whys" of self-harm. J Youth Adolesc 34.

28. Madge N (2011) Psychological characteristics, stressful life events and deliberate self-harm: Findings from the child \& adolescent self-harm in Europe (CASE) study. Eur Child Adolesc Psychiatry 20: 499-508.

29. Marcelli D, Braconnier A (1983) Adolescence and psychopathology. Climepsi Publishers, Lisbon, Portugal.

30. Mead M (1961) Coming of age in Samoa: A Psychological study of primitive youth for western civilization. Perennial Classics, New York, USA.

31. Monteiro P (2014) Psychology and psychiatry of childhood and adolescence. Lidel, Lisbon, Portugal.

32. Muehlenkamp JJ, Claes L, Havertape L, Plener PL (2012) International prevalence of non-suicidal self-injury and deliberate self-harm. Child Adolesc Psychiatry Ment Health 6:10.

33. Swannell SV, Martin GE, Page A, Hasking P, St John MJ (2014) Prevalence of nonsuicidal self-injury in nonclinical samples: Systematic review, metaanalysis and meta-regression. Suicide Life Threat Behav 44: 273-303.

34. Taliaferro LA, Muehlenkamp JJ, Borowsky IW, McMorris BJ, Kugler KC (2012) Factors distinguishing youth who report self-injurious behavior: A population-based sample. Acad Pediatr 12: 205-213.

35. Tatnell R, Kelada L, Hasking P, Martin G (2014) Longitudinal analysis of adolescent NSSI: The role of intrapersonal and interpersonal factors. J Abnorm Child Psychol 42: 885-896.

36. Thapar A, Pine DS, Leckman JF, Scott S, Snowling MJ, et al. (2015). Rutter's child and adolescent psychiatry. (6th edn.), John Wiley \& Sons, West Sussex, UK.

37. Van Camp I, Desmet M, Verhaeghe P (2011) Gender differences in nonsuicidal self-injury: Are they on the verge of leveling off? IPCSIT 23: 28-34.

38. Washburn J (2011) Psychotherapeutic approaches to non-suicidal selfinjury in adolescents. Child and Adolescent Psychiatry and Mental Health, 6:14, 1-8.

39. World Health Organization (1992) The ICD-10 classification of mental and behavioural disorders. Geneva

40. Yates TM (2004) The developmental psychopathology of self-injurious behavior: Compensatory regulation in posttraumatic adaptation. Clin Psychol Rev 24: 35-74.

41. Zetterqvist M (2015) The DSM-5 diagnosis of nonsuicidal self-injury disorder: A review of the empirical literature. Child Adolesc Psychiatry Ment Health 9: 31 .

42. Zubin J, Spring B (1977) Vulnerability: A new view of Schizophrenia. J Abnorm Psychol 86: 103-126. 